\title{
Thyrotoxic dilated cardiomyopathy: personal experience and case collection from the literature
}

\author{
Giuseppina Molinaroํㅜ, Renato De Vecchis², Elio Badolati and Raffaele Giannattasio ${ }^{3}$ \\ 1 UOC Internal Medicine, The Pellegrini Hospital, Naples, Italy; ${ }^{2}$ Medical and Polyspecialist Centre, Department of \\ Cardiology, DSB 29 "S.Gennaro dei Poveri Hospital", Naples, Italy; ${ }^{3}$ Medical and Polyspecialist Centre, Department of \\ Endocrinology and Metabolic Disorders, DSB 29 "S.Gennaro dei Poveri Hospital", Naples, Italy
}

Correspondence should be addressed to $\mathrm{R}$ De Vecchis

Email

devecchis.erre@virgilio.it

\section{Summary}

The authors examine several reports of the literature concerning thyrotoxic dilated cardiomyopathy. In particular, it is pointed out that this clinical manifestation of hyperthyroidism is rare in readily diagnosed and properly treated hyperthyroidism. Case reports are analyzed comparatively. A case deriving from the direct experience of the authors is also presented.

\section{Learning points:}

- Dilated cardiomyopathy has been reported as the initial presentation of hyperthyroidism in only $6 \%$ of patients although $<1 \%$ developed severe LV dysfunction.

- Clinical picture of thyrotoxic dilated cardiomyopathy can degenerate into an overt cardiogenic shock sometimes requiring the use of devices for mechanical assistance to the circulation, or extracorporeal membrane oxygenation.

- For thyrotoxic dilated cardiomyopathy, evidence-based pharmacologic measures valid for heart failure should always be supplemented by the administration of specific thyroid therapies such as thionamides (methimazole, carbimazole or propylthiouracil), whose relatively long latency of action should be supported by the i.v. administration of small doses of beta-blocker.

- In cases of cardiogenic shock, the administration of beta-blocker should be carried out only after the restoration of satisfactory blood pressure levels- with the prudent use of synthetic catecholamines, if necessary.

The present article illustrates a collection of cases from the literature plus one case deriving from the Authors' direct experience, all of them having thyrotoxic cardiomyopathy as their subject. It describes a collection of cases characterized by unusual presentation of the hyperthyroidism with the clinical picture of thyrotoxic cardiomyopathy $(1,2,3,4,5,6)$, albeit a fair polymorphism emerges from the case comparison due to comorbid conditions, able to mislead the diagnostic work-up.

\section{Case presentation}

The report by Abbasi et al. (7) is centered around the case of a 34-year-old Hispanic male, diagnosed with Graves' disease three years before, who presented to the emergency room with complaints of generalized weakness, palpitations, chest pain and multiple episodes of nausea and vomiting. On presentation, the patient was tachycardiac and had a precordial systolic flow murmur, while the ECG showed atrial flutter. In addition, cardiac troponin was $0.04 \mathrm{ng} / \mathrm{mL}$ 
and echocardiogram revealed severely depressed left ventricular function with an ejection fraction of $26-30 \%$. Of note, the prospect of thyroid function was markedly altered due to the steep rise of triiodotyronine with subnormal TSH: thyroid-stimulating hormone (TSH) $0.02 \mu \mathrm{IU} / \mathrm{mL}$, Free Triiodothyronine (T3) $25.14 \mathrm{pg} / \mathrm{mL}$ and free thyroxine (T4) $5.23 \mathrm{ng} / \mathrm{dL}$. In addition, physical examination showed upper and lower extremity weakness graded with a three out of five on the strength scale. The therapy included propranolol, along with propylthiouracil and hydrocortisone to prevent thyroid storm. Since blood work showed a potassium of 1.8 millimoles per liter (mmol/L), a central line was placed for rapid potassium repletion. Management was continued with methimazole plus propranolol. Physical exam showed an increase in the upper and lower extremity muscle strength to five out of five. The patient discharged on day nine with methimazole, propranolol and lisinopril, with an outpatient follow-up appointment. This report is very remarkable because it encompasses two life-threatening complications of Flajani-Graves-Basedow disease: the truly rare thyrotoxic periodic paralysis and the thyrotoxic dilated cardiomyopathy.

In the description made by Meregildo Rodriguez et al. (8) a case of simultaneous presentation of decompensated thyrotoxicosis, diabetic ketoacidosis (DKA) and frank thyrotoxic dilated cardiomyopathy is reported. A patient presented to emergency department with drowsiness, alteration of breathing (tachypnea and Kussmaul's breathing) and severe hypotension. He had a history of malaise, headache, fever, and generalized body pain during the last 6 days. Laboratory findings were serum glucose: $460 \mathrm{mg} / \mathrm{dL}$, urea: $115 \mathrm{mg} / \mathrm{dL}$, creatinine: $1.3 \mathrm{mg} / \mathrm{dL}$, hemoglobin: $12.9 \mathrm{~g} / \mathrm{dL}$, hematocrit: 40\%, platelets: $198,000 / \mathrm{mm}^{3}$, white blood cells: $10,100 /$ $\mathrm{mm}^{3}, \mathrm{pH}: 6.99$, TSH: $0.024 \mu \mathrm{IU} / \mathrm{L}$, free-T4: $2.16 \mathrm{ng} /$ $\mathrm{dL}$ (reference range (RR): $0.82-1.63 \mathrm{ng} / \mathrm{dL}$ ), total-T3: $0.18 \mathrm{ng} / \mathrm{mL}$ (RR: 0.5-2.0 ng/mL), free-T3: $0.42 \mathrm{pg} / \mathrm{mL}$ (RR: 2.1-3.8 pg/mL) Echocardiography showing borderline pulmonary artery systolic pressure $(35 \mathrm{mmHg})$, severe LV systolic dysfunction (LV ejection fraction 35\%), with left ventricular global hypokinesia and mitral inflow pattern of restrictive type. Based on these results, normal saline, insulin infusion plus potassium chloride, sodium bicarbonate, norepinephrine, hydrocortisone $100 \mathrm{mg}$ every $8 \mathrm{~h}$, methimazole $20 \mathrm{mg}$ every $8 \mathrm{~h}$, and Lugol's solution 10 drops every $8 \mathrm{~h}$, were prescribed. Based on physical examination, chest X-ray (CXR), and progressive decrease in partial oxygen pressure compatible with acute lung edema, i.v. furosemide $20 \mathrm{mg}$ every $12 \mathrm{~h}$ was administered for 2 days. On the 6th day of treatment, hydrocortisone and Lugol's solution were stopped, and methimazole was reduced by half. The patient was discharged with almost complete recovery. This report is suggestive of a patient's failure to adhere to the previously prescribed insulin therapy, in conjunction with the triggering of a thyrotoxic crisis due to previously undiagnosed nodular goiter. In fact, the clinical picture is dramatically improved by the administration of methimazole, that is, a drug not previously prescribed to patient because he had never received the correct diagnosis of 'toxic nodular goiter'.

In the report by Alam et al. (9) the case of a 65-yearold woman referred urgently from primary care with worsening breathlessness, tachyarrhythmia as per atrial fibrillation and newly diagnosed left bundle branch block (LBBB) is described. She had a background of type 2 diabetes, asthma and hypertension. Initial ECG revealed atrial fibrillation with fast ventricular rate on the background of LBBB. ECHO findings were consistent with a state of systolic impairment. Initial testing including checking thyroid function test revealed hyperthyroidism. It became evident that this patient had thyrotoxic dilated cardiomyopathy. Chest X-ray: cardiomegaly, left-sided pleural effusion, prominent pulmonary hila, X-ray image suggestive of early pulmonary edema. Echocardiogram: showed severely dilated left atrium with severe impairment to overall left ventricle systolic function (ejection fraction 24\% using biplane Simpson method). Moderate tricuspid regurgitation and mild mitral regurgitation. The thyroid function test revealed: thyroid-stimulating hormone (TSH): $<0.01(0.35-3.50 \mathrm{mU} / \mathrm{L})$, thyroxine (free T4): 28.5 (7.5-21.1 pmol/L), triiodothyronine (free T3): 8 (3.8$6.0 \mathrm{pmol} / \mathrm{L})$. Thus, thyrotoxic dilated cardiomyopathy was diagnosed. The patient was started on antithyroid medications (carbimazole $20 \mathrm{mg}$ once daily), beta-blocker (bisoprolol $2.5 \mathrm{mg}$ once daily), ramipril $2.5 \mathrm{mg}$ once daily and i.v. furosemide $80 \mathrm{mg}$ twice daily. As the patient developed bronchospasm, bisoprolol was later switched to ivabradine $2.5 \mathrm{mg}$ twice daily which was slowly uptitrated to $7.5 \mathrm{mg} \times$ twice daily. The dose of i.v. furosemide was decreased and switched to bumetanide $1 \mathrm{mg}$ once daily.

In the further course of hospitalization, the patient's condition improved over the next 3-4 days, with complete resolution of fluid overload, and heart rate slowed down to 70 b.p.m.

She turned back to sinus rhythm, maintaining her heart around 50-60 b.p.m.

Her repeat echocardiogram showed moderate to severe left ventricular (LV) impairment with a decrease in 
tricuspid and mitral regurgitation. Her ejection fraction was improved to $37 \%$ (biplane Simpson method).

In the report by Allencherril et al. (10) there is a description of the dramatic picture that occurs in the presence of thyrotoxic heart failure with severe hypotension. The patient described was already known as an individual affected by Graves' disease, however, he had omitted to take the previously prescribed methimazole for the last 45 days. The clinical scenario was initially characterized by dyspnoea and palpitations with an electrocardiographic picture of atrial flutter 2:1 with a ventricular response of $160 \mathrm{btt} / \mathrm{min}$. Laboratory evaluation showed suppressed thyroid-stimulating hormone and markedly elevated free thyroxine (T4) and triiodothyronine (T3). Despite the rapid resumption of therapy with antithyroid drug (propylthiouracil) and propranolol, worsening dyspnea arose with an echocardiographic picture showing severely depressed left ventricular ejection fraction (about 20\%), together with left atrial dilation and functional mitral insufficiency. After two days of antithyroid and beta-blocker therapy, cardiac decompensation deteriorated further so as to turn to a frank picture of cardiogenic shock, complicated after several hours by monomorphic ventricular tachycardia (VT). The VT was converted to sinus rhythm by means of transthoracic electric shock, but the subsequent administration of inotropic drugs, namely epinephrine, norepinephrine and vasopressin at congruous doses via i.v. infusion, was not sufficient to raise the pressure up to normal levels.

Thus, an adequate resumption of blood flow for the various organs and systems was not achieved. In particular, severe renal failure developed along with the persistence of heart failure.

Therefore, it was necessary to resort to left ventricular mechanical assistance techniques such as intra-aortic balloon pump (IABP) and venoarterial extracorporeal membrane oxygenation (VAECMO).

After 6 days of uninterrupted therapy with VA-ECMO it was possible to identify a partial retrieval of the LVEF, which attained values of $35-39 \%$. The subsequent evolution was a further increase in LVEF up to values of $45-49 \%$ at the 11th day. The patient was extubated 2 days after decannulation from ECMO. At discharge, he returned to baseline cognitive status and functional capacity.

The case-report derived from our direct observation refers to a male sex patient, aged 60 years with a clinical picture of cardiogenic shock related to severe left ventricular dilation and dysfunction. The ECG showed atrial fibrillation at an average ventricular rate

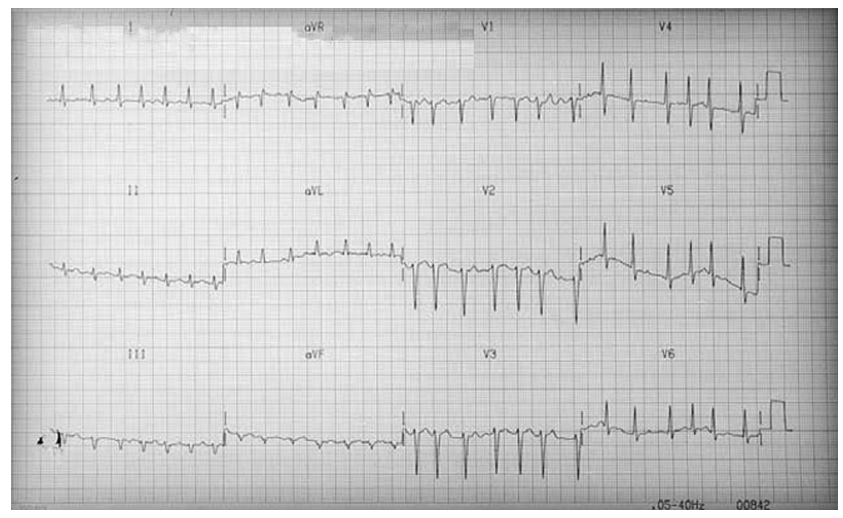

Figure 1

ECG at admission.

of 180 b.p.m. (Fig. 1). Radiography of thorax showed cardiomegaly and pulmonary edema (Fig. 2).

Transthoracic echocardiogram showed dilation of the left ventricle with severe impairment of global and segmental contractility (ejection fraction 15\%) and slight mitral insufficiency.

Emergency blood chemistry tests showed normal blood count, blood sugar: $128 \mathrm{mg} / \mathrm{dL}$, azotemia: $37 \mathrm{mg} /$ dL, GOT: 303 U/L, GPT: 356 U/L, Na: 139 mEq/L, K: 4.4 $\mathrm{mEq} / \mathrm{L}$, total bilirubinemia: $1.86 \mathrm{mg} / \mathrm{dL}$; there was also a serious picture of respiratory and metabolic acidosis. The patient was intubated, mechanically ventilated and treated with bicarbonates, digoxin, furosemide, dobutamine, heparin. A hemodynamic balance after $24 \mathrm{~h}$, obtained by positioning a Swan-Ganz catheter in the right cardiac sections, documented: cardiac output 7.6 L/min; pulmonary capillary pressure $11 \mathrm{mmHg}$, pulmonary pressure $40 / 24 \mathrm{mmHg}$, average $29 \mathrm{mmHg}$. Coronary angiography documented a substantially

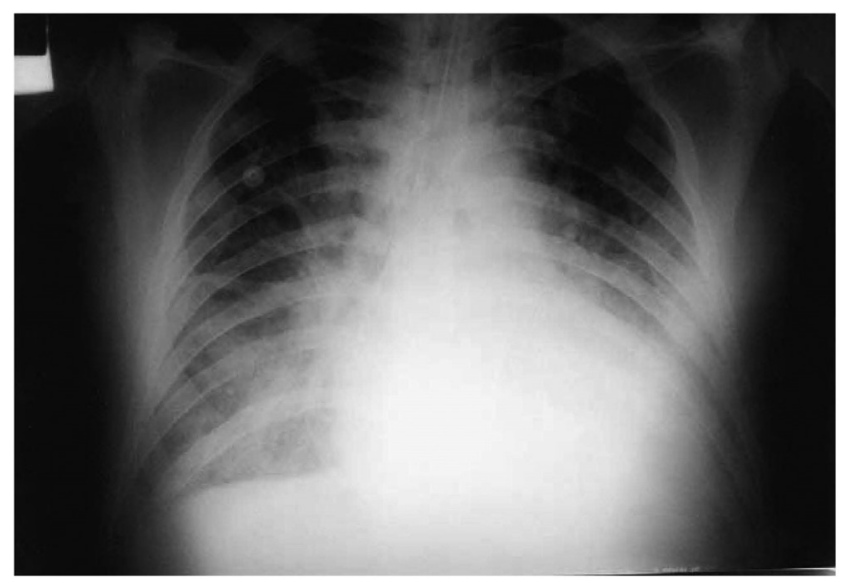

Figure 2

Thorax X-ray at admission. 


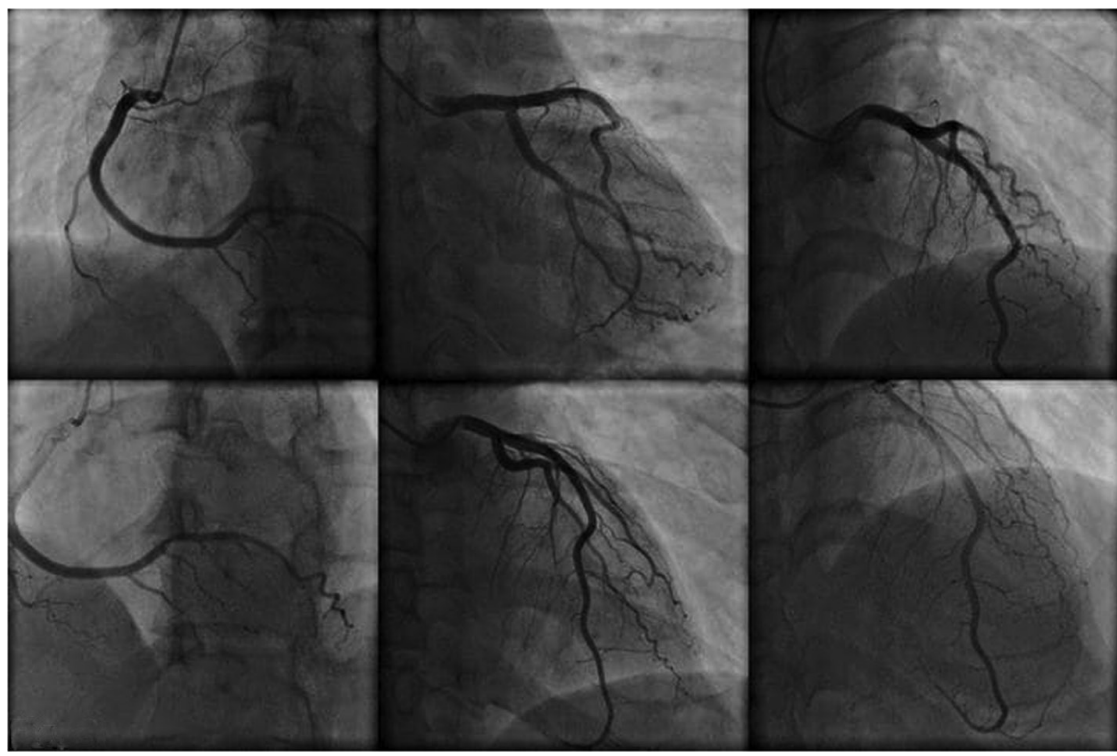

undamaged coronary tree,that is, free from any hemodynamically significant stenosis (Fig. 3). The diagnosis of thyrotoxicosis, clinically suspected, was confirmed by the dosage of thyroid hormones: FT4 4.7 ng/dL (RR: 0.6-1.7 ng/dl); FT3 $1.9 \mathrm{pg} / \mathrm{mL}$ (RR: 2.2-5.8 $\mathrm{pg} / \mathrm{mL}$ ); TSH <0.05 mU/mL (RR: 0.2-4 mU/mL); T4 125 ng/mL (RR: 40-120 ng/mL); T3 $1.5 \mathrm{ng} / \mathrm{mL}$ (RR: 0.6-2 $\mathrm{ng} / \mathrm{mL})$. Thyroid antibodies were normal; moreover, the inflammation indexes were normal. Methimazole $10 \mathrm{mg} /$ day therapy was initiated in two administrations and, under careful hemodynamic monitoring, small doses of propranolol IV were administered $(0.05 \mathrm{mg} / \mathrm{kg}$ body weight). In the following days there was a progressive improvement in hemodynamic conditions. On the fifth day, atrial fibrillation turned into atrial flutter, while an echocardiographic examination documented a reduction in the size of the left ventricle and an ejection fraction of $35 \%$. On the seventh day the patient was extubated. Subsequently (ninth day) the atrial flutter was treated with synchronic cardioversion with direct low-energy current $(75 \mathrm{~J})$ which resulted in the conversion to sinus rhythm (Fig. 4). On the tenth day the patient was discharged in good general condition, with sinus rhythm and completely regressed prior pulmonary edema (Fig. 5), in therapy with methimazole, ACE inhibitors and furosemide, with the diagnosis of thyrothoxic dilated CMP during Plummer disease. On occasion of the checks carried out at 6 and 12 months, the patient was asymptomatic, with sinus rhythm, euthyroid and with echocardiogram which documented normal size of the ventricular cavities, with restored normality of the segmental and overall parietal kinetics of the left ventricle (LVEF: 52\%).

\section{Figure 3}

Coronary angiograms documenting substantial integrity of the three major coronary branches explored with coronarography performed immediately before the patient's clinical picture degenerated into shock.

\section{Discussion}

In the case-report of Abbasi et al. (7) and Allencherril et al. (10) a condition of hyperthyroidism was already known at the time of the onset of the thyrotoxic crisis. In the remaining three casereports - the one by Meregildo Rodriguez et al. (8), the one by Alam ST et al. (9) and ours - the condition of hyperthyroidism was unknown to the patient and doctors at the time of hospitalization, so that thyrotoxic dilated CMP has been the initial manifestation of hyperthyroidism (6).

In three of the five case reports, that of Meregildo Rodriguez et al. (8), that of Allencherril et al. (10) and that described by our team, there is a low-output syndrome requiring the use of i.v. inotropes. Therefore paradoxically norepinephrine in the report by Meregildo Rodriguez et al. (8), dobutamine in our experience and the association of epinephrine, norepinephrine and

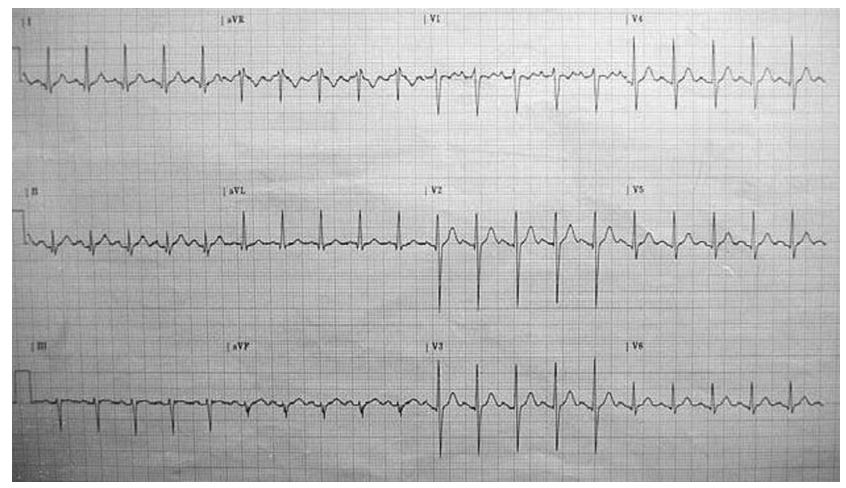

Figure 4

ECG after electrical cardioversion. 


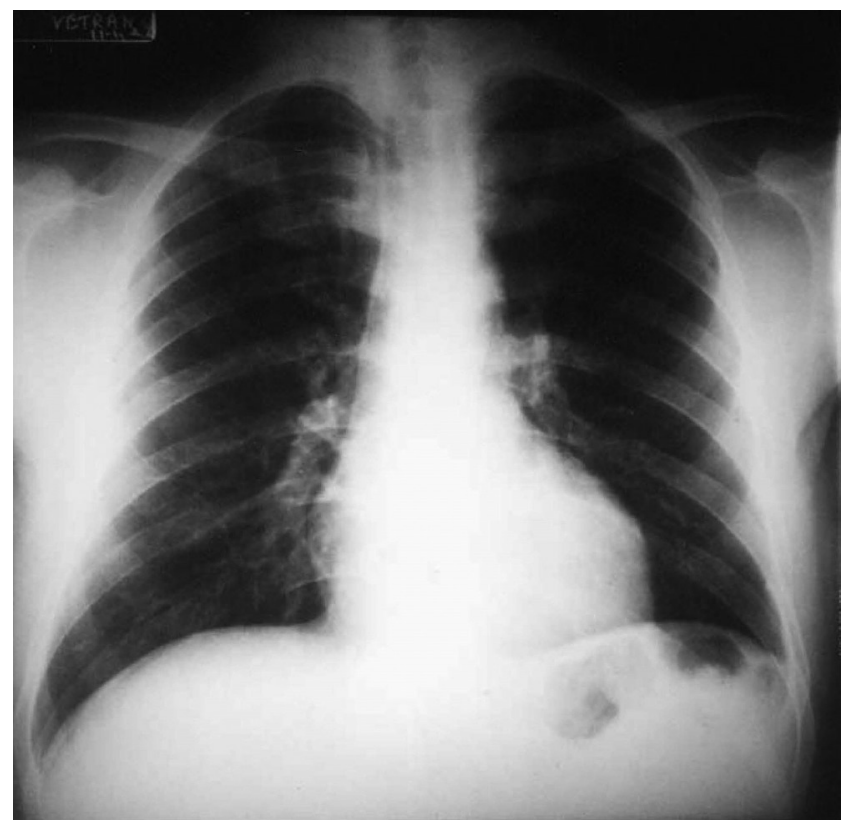

Figure 5

Thorax X-ray at discharge.

vasopressin in the report by Allencherril et al. (10) are used to counteract the shock even in the presence of massive adrenergic stimulation due to the excess of thyroid hormones.

The need of the ECMO, described in the study by Allencherril et al. (10), is indicative of the huge severity of multiorgan deterioration that thyrotoxicosis has caused in this case. In fact, the patient described in the report, suffering from Graves' disease but who had omitted to take the prescribed drugs, exhibits rapidly worsening systolic heart failure (left ventricular ejection fraction $=20 \%$ ) from thyrotoxic dilated cardiomyopathy, to which are added acute renal failure and shock, the latter being not responsive to sympathomimetic amines. Despite the severe upheaval of the acute phase, after weaning from the ECMO, the restoration of a normal left ventricular ejection fraction is achieved under the effect of the reintroduction of thionamides into the therapy.

In all the cases presented, there was a recovery of the pump function after the introduction of antithyroid drugs (propylthiouracil, methimazole or carbimazole) into the patient's therapeutical scheme. The relatively rapid restoration of normal cardiac volumes is a typical aspect of the evolution of thyrotoxic dilated CMP when it is recognized and treated promptly $(6,11,12,13)$. Instead, in the majority of dilated cardiomyopathies of other origin, the early recognition of the pathology with the choice of appropriate treatment does not warrant per se any favourable regression of cardiac remodeling as well as does not guarantee a restoration of the pump function.

Finally, it is necessary to consider the point that cardiac decompensation of thyrotoxic cardiomyopathy, albeit benefitting from the evidence-based therapy consisting of anti RAAS drugs, namely ACE-inhibitors, angiotensin receptor blockers or mineralocorticoid receptor antagonists and/or beta-blockers cannot be effectively antagonized without the paramount support of the antithyroid drugs. In other words, no measure is sufficient to stop thyrotoxic cardiac decompensation if hormonal hyper-activity persists and is not corrected by highly specific measures, namely thyroid-suppressive drugs, radioiodine or thyroidectomy. In addition, in the presence of low-output syndrome, beta-blockers could be added to the therapy only after adequately correcting the hypotension.

Overall, these observations are able to debunk the concept that thyrotoxic heart failure is always characterized by high cardiac output. In fact, this statement is superficial because it is not suitable for cases of thyrotoxic dilated cardiomyopathy, that is, about $6 \%$ of all clinical presentations of hyperthyroidism, in which heart failure is characterized by a depressed left ventricular ejection fraction. Furthermore, although rare in the course of a thyrotoxic crisis during Graves' disease, the occurrence of a low cardiac output syndrome with cardiogenic shock has been described. In this case the use of inotropic drugs is required and, in the refractory forms, the resort to devices for supporting the circulation and lung ventilation such as ECMO has been also recommended.

\section{Concluding remarks}

Thyrotoxic dilated cardiomyopathy is part of the spectrum of clinical manifestations of hyperthyroidism. It represents the conclusive stage of the alterations of remodeling and of the function of the left ventricle in case of hyperthyroidism not timely diagnosed and/or not adequately treated. It is usually associated with a condition of heart failure with reduced left ventricular ejection fraction (HFREF) and low cardiac output. Thyrotoxic dilated cardiomyopathy seems to have greater room for improvement and recovery compared to the other varieties of dilated cardiomyopathy (idiopathic, post-ischemic, valvular, etc.). Therapy, alongside RAAS inhibitor drugs, compulsorily includes the administration of beta-blockers and antithyroid drugs (methimazole, carbimazole, propylthiouracil). 


\section{Declaration of interest}

The authors declare that there is no conflict of interest that could be perceived as prejudicing the impartiality of the research reported.

\section{Funding}

This research did not receive any specific grant from any funding agency in the public, commercial or not-for-profit sector.

\section{Patient's consent}

Written informed consent has been obtained from the patient for publication of this case report.

\section{Author contribution statement}

All authors have contributed in an equal manner to conception and drafting of the paper as well as revising it critically for important intellectual content.

\section{References}

1 Osman F, Franklyn JA, Holder RL, Sheppard MC \& Gammage MD. Cardiovascular manifestations of hyperthyroidism before and after antithyroid therapy: a matched case-control study. Journal of the American College of Cardiology 200749 71-81. (https://doi. org/10.1016/j.jacc.2006.08.042)

2 Goland S, Shimoni S \& Kracoff O. Dilated cardiomyopathy in thyrotoxicosis. Heart 199981 444-445. (https://doi.org/10.1136/ hrt.81.4.444)

3 Bristow MR, Saxon LA, Boehmer J, Krueger S, Kass DA, De Marco T, Carson P, DiCarlo L, DeMets D, White BG, et al. Cardiacresynchronization therapy with or without an implantable defibrillator in advanced chronic heart failure. Comparison of
Medical Therapy, Pacing, and Defibrillation in Heart Failure (COMPANION) Investigators. New England Journal of Medicine 2004 350 2140-2150. (https://doi.org/10.1056/NEJMoa032423)

4 De Vecchis R, Ariano C, Di Biase G \& Noutsias M. Sacubitril/valsartan for heart failure with reduced left ventricular ejection fraction: a retrospective cohort study. Herz 201944 425-432. (https://doi. org/10.1007/s00059-017-4671-1)

5 Kim S, Seol SH, Kim YS, Kim DK, Kim KH \& Kim DI. Thyrotoxicosis induced cardiogenic shock rescued by extracorporeal membrane oxygenation. Journal of Geriatric Cardiology 201815 203-204. (https://doi.org/10.11909/j.issn.1671-5411.2018.02.003)

6 Siu CW, Yeung CY, Lau CP, Kung AW \& Tse HF. Incidence, clinical characteristics and outcome of congestive heart failure as the initial presentation in patients with primary hyperthyroidism. Heart 2007 93 483-487. (https://doi.org/10.1136/hrt.2006.100628)

7 Abbasi AA, Chandar P, Shankar S, Gupta SS \& Kupfer Y. Thyrotoxic periodic paralysis and cardiomyopathy in a patient with Graves' disease. Cureus 201810 e2837. (https://doi.org/10.7759/cureus.2837)

8 Meregildo Rodriguez ED, Gordillo Velásquez LI \& Alvarado Moreno JG. Diabetic ketoacidosis associated with thyroxine $\left(\mathrm{T}_{4}\right)$ toxicosis and thyrotoxic cardiomyopathy. Medicina $2018 \mathbf{5 4} 93$. (https://doi.org/10.3390/medicina54060093)

9 Alam ST \& Zaman J. Case study of thyrotoxic cardiomyopathy. BMJ Case Reports 201912 e228896. (https://doi.org/10.1136/bcr-2018-228896)

10 Allencherril J \& Birnbaum I. Heart failure in thyrotoxic cardiomopathy: extracorporeal membrane oxygenation treatment for Graves' disease. Journal of Extra-Corporeal Technology 201547 231-232.

11 Kantharia BK, Richards HB \& Battaglia J. Reversible dilated cardiomyopathy: an unusual case of thyrotoxicosis. American Heart Journal 1995129 1030-1034. (https://doi.org/10.1016/00028703(95)90128-0)

12 Bauerlein EJ, Chakko CS \& Kessler KM. Reversible dilated cardiomyopathy due to thyrotoxicosis. American Journal of Cardiology 199270 132. (https://doi.org/10.1016/0002-9149(92)91412-w)

13 Klein I. Endocrine disorders and cardiovascular disease. In Braunwald's Heart Disease: A Textbook of Cardiovascular Medicine, 11th ed., pp. 1813-1820. Eds DP Zipes, P Libby, R Bonow, DL Mann, GF Tomaselli, E Braunwald, et al. Philadelphia, PA: W.B.Saunders, 2018.

Received in final form 23 July 2020

Accepted 5 November 2020 